Proceedings of the XXIII Conference on Applied Crystallography, Krynica Zdrój, Poland, September 20-24, 2015

\title{
Crystal Perfection Studies of Single Crystal Superalloy Turbine Blades by X-Ray Diffraction Methods
}

\author{
K. GancarczyK ${ }^{a, *}$, R. Albrecht ${ }^{b}$, W. Bogdanowicz ${ }^{b}$ And J. Sieniawski ${ }^{a}$ \\ ${ }^{a}$ Rzeszów University of Technology, Department of Material Science, Faculty of Mechanical Engineering \\ and Aeronautics, al. Powstańców Warszawy 12, 35-959 Rzeszów, Poland \\ ${ }^{b}$ University of Silesia, Institute of Materials Science, 75 Pułku Piechoty 1A, 41-500 Chorzów, Poland \\ In the paper the crystal structure of single crystal CMSX-4 blade casts, applied in high pressure turbine of \\ aircraft engines was analyzed. The longitudinal section of blade, cast at withdrawal rate of $3 \mathrm{~mm} / \mathrm{min}$ was used \\ as a sample. During the conducted research, following X-ray diffraction methods were applied: EFG $\Omega$-scan, \\ Auleytner X-ray topography and analysis of diffraction reflex profile ("rocking curve"). The authors determined \\ crystal orientation in entire blade casts on the basis of set criterion concerning values of angle $\alpha$ - deviation of \\ [001] direction from the direction of cast withdrawal. Conclusions concerning the crystal structure quality of the \\ blade were drawn based on results from three different research methods. Local changes in crystal orientation on \\ the surface of blade cast, also areas with significant structure defect degree and the presence of internal stresses \\ were characterized.
}

DOI: 10.12693/APhysPolA.130.1088

PACS/topics: 61.66.Dk, 61.05.cp

\section{Introduction}

Single crystal casts made of nickel base superalloy are used for aircraft engine hot section components, i.e. blades of first and second turbine stage, due to their specific mechanical and thermal properties - mainly heat and creep resistance. They are particularly exposed to service in extremely aggressive conditions with the presence of high loads, high temperature and oxidizing gases environment. During exploitation in such conditions creep process takes place, which is a main factor of blades failure. Due to the complexity of aircraft engine design, production and maintenance costs, also necessity to ensure passengers security, engine elements have to be manufactured using high quality materials which are suitable for aggressive service conditions. Blades used in the first and second stage of turbine are considered as elements therefore quality control and assessment of crystal structure with the use of X-ray diffraction methods is particularly important [1-3].

\section{Experimental}

CMSX-4 nickel based superalloy was prepared for the investigation. The single crystal blades were cast during a process by Bridgman method at withdrawal rate of $3 \mathrm{~mm} / \mathrm{min}$. The manufactured single crystal blade casts were afterwards prepared for analysis using X-ray diffraction. The investigation was carried out on the blade longitudinal section which was prepared for analysis by cutting and mechanical polishing.

The measurement of crystal orientation was performed on single crystal blade cast using EFG $\Omega$-scan X-ray

\footnotetext{
*corresponding author; e-mail: KamilGancarczyk@prz.edu.pl
}

diffraction method [4]. The deviation angle $\alpha$ between [001] direction and withdrawal direction of single crystal material was measure of crystal orientation. The research was carried out with the use of X-ray diffractometer ODEFG. X-ray topograms of longitudinal section of blade casting were obtained using the Auleytner method with divergent X-ray beam. Following parameters were applied: characteristic radiation $\mathrm{Cu} K_{\alpha}$, exposure time of $0.5 \mathrm{~h}$, sample-to-film distance $100 \mathrm{~mm}$, oscillation range of sample and film $4^{\circ}$. Reflexes 002 , from crystallographic planes $\{001\}$, and 113 were performed for analysis. The authors determined the quality of crystal structure of blade casting based on the analysis of reflexes profiles which were obtained with the use of X-ray diffraction. Application of shutter in the research allowed to form a rectangular $\left(1 \times 8 \mathrm{~mm}^{2}\right)$ X-ray beam. The characteristic radiation $\mathrm{Cu} K_{\alpha}$ was applied to diffraction from 004 reflex for angle value $\theta=59.5^{\circ}$.

\section{Results and discussion}

The analysis of $\alpha$ angle on the blade surface which was casted in a process with withdrawal rate of $3 \mathrm{~mm} / \mathrm{min}$ showed the value to be in a range $6.2-7.3^{\circ}$. The distribution of $\alpha$ angle values indicates formation of crystal orientation on the left side of upper part of blade root (E) and whole airfoil tip (F and G) (Fig. 1). The value of subgrain angle between blocks is $0.5^{\circ}$ for the upper part of root and $1^{\circ}$ for the airfoil. Additionally, the line analysis of $\alpha$ angle changes were performed from the area shown in Fig. 1 (dotted line). The values of $\alpha$ angle show depending on the distance from the beginning of blade casting: for the root the angle takes values from the range 6.6-6.75 ${ }^{\circ}$, whereas for airfoil — from 6.6-7.25 (Fig. 2). In the airfoil this value increases significantly in its upper part from $6.7^{\circ}$ up to $7.25^{\circ}$. 


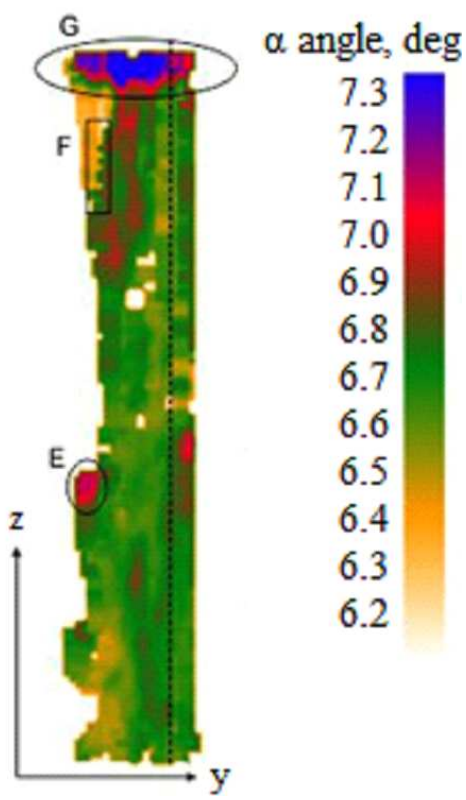

Fig. 1. The distribution of $\alpha$ angle value on the surface of longitudinal section of single crystal blade made of CMSX-4 nickel superalloy. Dotted line - area chosen for line profile analysis.

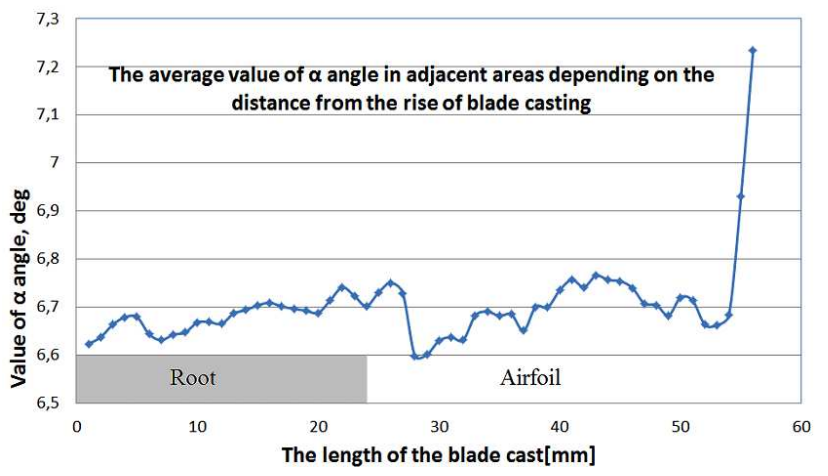

Fig. 2. The value of $\alpha$ angle depending on the distance from the rise of blade cast.

X-ray topograms were obtained for the blade longitudinal section (Fig. 3). The analysis of topograms made possible to determine the subgrain misorientation areas and distribution of structural defects on the whole blade cross-section. The upper part of airfoil are areas which stand out significantly in terms of structure defects $-\mathrm{F}^{\prime}$, $\mathrm{G}^{\prime}$. The subgrain boundaries in the blade root are visible mainly in area $\mathrm{E}^{\prime}$ (Fig. 3a). Additionally, on the input of selector to root lack of contrast was stated - L. The analysis of reflexes profile originating from $\{001\}$ planes was carried out for A-D sections (Fig. 3b). Defected microstructure of single crystal influences the shape of diffraction line - multiple orientation results in few maxima. Broadening of reflexes also indicate the occurrence of internal stresses. The reflexes profiles originate from $\mathrm{X}$-ray diffraction carried out in blade sections designated, a)

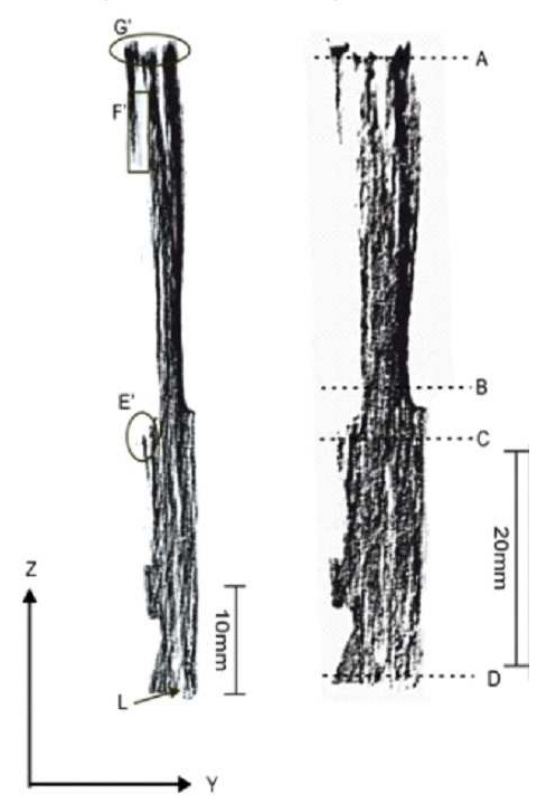

Fig. 3. The X-ray topograms obtained for singlecrystal blade on its longitudinal section: (a) reflex 002, (b) reflex 113, A, B, C, D - sections for the reflex profile analysis.

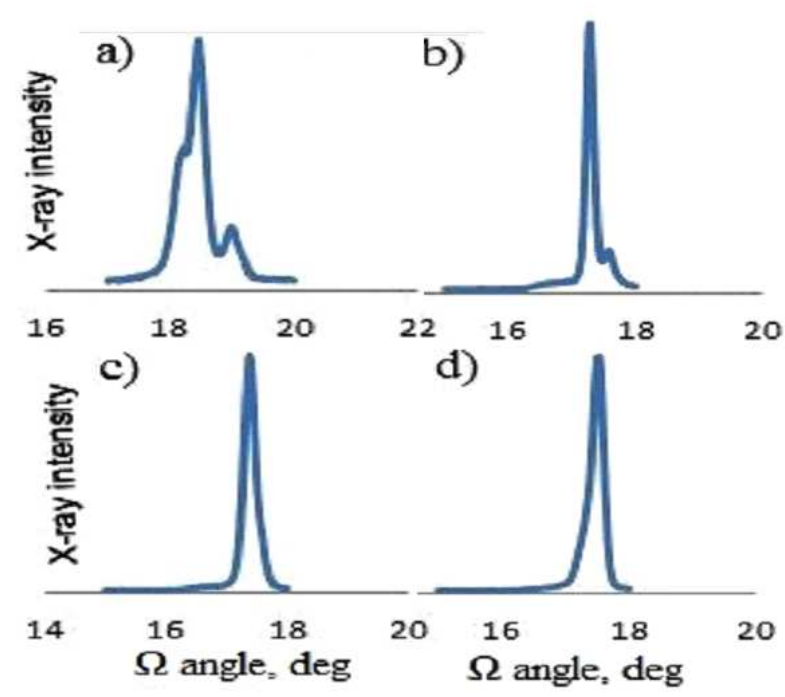

Fig. 4. The profiles of diffraction reflex from the diffraction on crystallographic planes $\{001\}$. Wide Xray slit $\left(1 \times 8 \mathrm{~mm}^{2}\right) \mathrm{Cu} K_{\alpha}(\lambda=0.1542 \mathrm{~nm})$.

accordingly, as A, B, C, and D (Fig. 3b). In the airfoil of blade (A, Fig. 4a), three maxima and largest broadening of reflex were observed. In cross-section designated as B (Fig. 4b) two maxima were detected. The areas of blade root ( $\mathrm{C}$ and $\mathrm{D}$ cross-sections, Fig. 4c,d) are characterized by one maximum and narrower reflexes profiles than airfoil. 


\section{Conclusions}

Single crystal blades castings made of nickel superalloys were analyzed using X-ray diffraction methods: $\Omega$ scan, X-ray topography, and "rocking curve" (analysis of diffraction reflexes profile). The correlation between results obtained with those techniques allows to draw the following conclusions:

- the values of $\alpha$ angles (deviation of [001] direction from the withdrawal direction of single crystal material) for the area of root and airfoil do not differ significantly along the casting length, except its end (airfoil) where $\alpha$ angle reached highest values;

- amount of defects in the structure increases with the length of blade casting. It is higher in airfoil than the root and reaches highest values in the upper part of airfoil;
- the analysis of profile of diffraction reflexes ("rocking curve") confirmed the research results obtained by X-ray topography and $\Omega$-scan mapping. The profiles of reflexes obtained with X-ray diffraction are broadened due to the presence of internal stresses, also they have two or three maxima in areas of misorientation.

\section{References}

[1] B. Dubiel, Microstructural Changes during Creep of Single-Crystalline Nickel-Base Superalloys, AGH University of Science and Technology Press, Kraków 2011.

[2] D. Szeliga, K. Kubiak, A. Burbelko, M. Motyka, J. Sieniawski, J. Mater. Eng. Perform. 23, 3 (2014).

[3] W. Bogdanowicz, R. Albrecht, A. Onyszko, J. Sieniawski, Solid State Phenom. 203-204, 63 (2013).

[4] K. Gancarczyk, R. Albrecht, Ch. Olesch, K. Kubiak, J. Sieniawski, Mater. Eng. 6, 208 (2015). 